\title{
E-Business Models in the Online Music Sector - A Survey of 10 European Countries
}

\author{
Cornelia Krueger \\ Faculty of Informatics, University of Koblenz-Landau, Germany \\ ckrueger@uni-koblenz.de \\ Paula M.C. Swatman \\ University of South Australia, Australia \\ paula.swatman@unisa.edu.au \\ Kornelia van der Beek \\ Faculty of Informatics, University of Koblenz-Landau, Germany \\ beek@uni-koblenz.de
}

\begin{abstract}
The online music market has changed significantly and fundamentally over the past few years, as more and more new players - many of them originally from other sectors - enter the market space of the original media companies. Although these new entrants provide the media companies with the opportunity to adapt their business to the new demands of the Internet, they are also competitors who are themselves able to offer music over the Net. In this paper we describe the current state of play in the online music sectors in Europe at May 2003. The outcomes are based on "expert talks" and an online survey. After initially discussing the justification for our chosen research approach, we describe the research design. We then report our findings. Finally we identify the key driving factors for online music today: the new competitive environment, the appropriate payment systems, the focus on core competences, end devices and the consumers.
\end{abstract}

\section{Introduction ${ }^{1}$}

The digital content market (and, in particular, the online news and music markets) has changed significantly and fundamentally over the past few years, as more and more new players - many of them originally from other sectors - enter the market space of the original media companies. Although these new entrants provide the media companies with the opportunity to adapt their business to the changing demands of the Internet, they are also competitors who are themselves able to offer music and/or news over the Net.

In this paper we describe the current state of play in the online music sector in ten European countries as at May 2003. After initially discussing the justification for our chosen research approach, we describe the research design and then report our findings from the first two phases of the project - the "Expert talks" we undertook with a small sample of companies active in the music industry and our web-based survey of the online music industry in Europe. The discussion of findings which

\footnotetext{
1 This paper is one of the outcomes of the "SimWeb" Project, which is funded by the European Commission's Fifth Framework to explore the possibility of developing a multiple-agent simulation as a strategic decision-making tool for SMEs in the online market-space, in the hope that this would provide an effective, but relatively inexpensive, alternative source of expert advice to companies unable to afford consulting services. Clearly, the SimWeb consortium needed to restrict the domain within which it would work - since fully grasping the underlying business models of even one online sector is a major task and, in the first instance, it was decided to work with two sectors only: online news and online music. The paper relates to only one component of SimWeb's total work programme: the exploration of the two industry sectors under study.
} 
follows combines the survey results themselves with literature-based data and analysis, in order to present a richer picture of the European online music industry. In the final section of the paper we identify the key driving factors for online music today.

\section{Literature Review}

A look at the existing literature concerning music distribution on the Internet highlights the importance of the business models being developed and used by music distributors and retailers. This body of literature has two major foci:

- $\quad$ one group of authors focuses on the phenomenon of peer-to-peer music access and its consequences for the music industry;

- the other group concentrates on the ways in which the music industry can (and should) react to everdeclining legal sales figures (compare [12]; [13]; [21]).

Research into the peer-to-peer phenomenon itself has a variety of emphases apart from the obvious discussion of its legality and impact on music sales: Kwok et al. [15] believe that business communities will embrace P2P technology for distribution of digital music only if the digital content is explicitly protected - suggesting that such protection might lead to a more commercial approach to P2P. Taking a rather different tack, Gehrke and Anding [7] have developed a peer-to-peer business model which they believe could make P2P legally and financially viable. All participants of the network charge for the content they offer and pay for the content they download and the model also includes a revenue share for the copyright holder. While difficult to implement effectively, their line of attack suggests that P2P might not always retain its negative image. Schoder and Fischbach [25] have an essentially technology-oriented slant on the issue, discussing the potential of P2P technology for mobile business and ubiquitous computing, especially where the aim is to establish communication in the absence of some form of central coordination. Lechner and Hummel [17], by contrast, take a sociological approach to $\mathrm{P} 2 \mathrm{P}$ architecture pointing out the community aspect. Although these authors do not propose a profitable business model, their research makes a valuable contribution to our understanding of $\mathrm{P} 2 \mathrm{P}$ file swappers - not as criminals, but as individuals searching for relationships and building a "community" with high potential (e.g. purchasing power).

Durlacher [4] is one of the authors whose research focuses on the music industry's situation. He believes that, in the long run, digital distribution will become the mainstream form of music distribution, with free downloading resisting all attempts by the music industry to destroy its influence. In his view, the only way to encourage consumer to buy digital music is to provide sufficient quality, convenience and added value to override the attractions of free access. Durlacher sees a key consumer market opportunity in the growth of functionality and storage capacity available via mobile devices.

Bhatia et al. [1] offer some advice to the 'labels' (the music distributors) regarding digital music distribution. They suggest that the music industry should consider the TV industry's business model and endeavour to transfer the concept of 'windowing' ' from the film to the music industry. These authors believe that labels will remain the centre of the recorded music industry, but will increasingly be forced to focus less on the physical distribution of albums and more on managing a smaller set of artists, multiple distribution channels and customer information. Lam \& Tan [16] take a slightly different tack, suggesting that record labels which distribute songs through both traditional and new channels could themselves become online retailers, using the "concept of anytime, anywhere, and anyhow" [16:66], and could focus on their core competency - music creation and the search for talent - as well as strengthening strategic alliances with Internet and media companies (to develop secure standards).

Clemons et al. [2] note that the theory of resourcebased advantage, applied within the context of the theory of newly vulnerable markets, indicates that the music industry is highly vulnerable. It doesn't only face the threat of P2P piracy, but is also at risk from artists and musicians wishing to distribute their own music directly via the Internet.

It is clear from this fairly brief summary of some of the more influential writers researching the evolution of the music industry that no matter whose theories are eventually proved correct, the music industry as we know it today will change almost out of recognition over the next few years. Rather than add to the growing body of speculation about how the music industry is developing, we have taken a different approach, providing a snap-shot view of the European online music industry as at the middle of 2003. We believe that the data we have obtained through interviews and survey providing a deeper and richer understanding of what is happening and where opportunities and threats are emerging - offering an orthogonal perspective to that provided by the more theoretical literature which is currently extant.

\footnotetext{
${ }^{2}$ Windowing refers to the way in which films are released on different TV stations during separate, carefully-sequenced time periods
} 


\section{Research Approach}

In the broadest sense, IS research methods can essentially be divided into positivist and interpretivist approaches. The key difference between these two research approaches is that the former rely primarily on observation, while the latter depend more on the researchers' own interpretations of their observations [6].

As we have suggested in the literature review above, we needed to gather 'hard' empirical data to provide a baseline for the simulation development being undertaken by our project partners and, realising that our approach would thus be essentially positivist in nature, we decided to follow Yin's recommendations as to method. Yin [29:6] suggested that ideal research strategies could be selected on the basis of a series of questions. For example, when the researcher wants to know "who", "what", "where" or "how many"; when the focus is on contemporary events; and when no control over events is required, then archival analysis and surveys are the recommended approaches. Once the question "how" is also asked, however, case studies become a more appropriate research method.

Our initial research design initially called for a survey of 10 European countries, followed by more in-depth analysis by means of face-to-face interviews in these same countries, to provide triangulation. Integrating several different research methods is a strategy used by many IS researchers (see, for example, [14]; [18]; and [5]), with the sequence and combination of the research methods selected depending on the characteristics of the problem under review.

Before we commenced this survey, however, we decided to gather some expert information on the two sectors under study from experienced and senior executives working in both the online news and online music sectors. These so-called 'expert talks' were undertaken in the two months before the launch of the survey and proved extremely useful in refining and improving the content of the survey questionnaires.

Our component of the SimWeb project was therefore divided into three phases:

- $\quad$ Phase 1: expert talks (scene-setting)

- Phase 2: online questionnaire (quantitative data collection)

- $\quad$ Phase 3: face-to-face interviews (qualitative data collection)

with each phase informing and adding to the subsequent phase. In this paper, we consider only the first two phases of this project (phase 3 is still underway) and restrict ourselves to discussing our findings from the online music sector.

\section{1. $\quad$ Phase One - Expert Talks}

We held detailed, face-to-face discussions - the 'expert talks' - with a total of 13 executives from 11 companies, mostly (but not entirely) located within Germany ${ }^{3}$. The expert talks were intended to provide a fundamental understanding of the music industry, enabling us to obtain a variety of perspectives from some of the most influential players within this industry (e.g. we interviewed representatives from: a major label, an independent music producer, an artist, the principal music association and a technology provider). The questions asked of these executives were largely open-ended and provided wide-ranging information on the structure of the two markets.

The expert talks also enabled us to identify the stakeholders in the online music market, which was a crucial factor in the design of the online questionnaire structure.

\subsection{Phase Two - the Online Questionnaire}

Questions were designed from both a theoretical and practical perspective. We had already undertaken a very extensive literature survey of both online business models and of the music industry (both on- and offline) and based many of our questions on this theoretical understanding (see De Vaus [3] for more detail on appropriate questionnaire design). Other questions were based on the responses we obtained during our Expert Talks. The content of the (primarily closed) questions concerned the respondent's business strategy, its products, selling strategy, network, customers and some general questions about the company.

We used a combination of email (for invitation) and web pages to obtain the data for the survey (a more thorough discussion of the use and usefulness of the Internet for survey data collection may be found, inter alia, in [26]; [19]; and [10]). The actual survey form was made available on a web site and made as user-friendly as possible.

Clearly, there was no guarantee that we had identified every company in the online music sector across our selected range of current and future European Union member countries. Nonetheless, since SimWeb is primarily directed towards the European market, the sample - which consisted of EU member countries, together with a selected group of Accession countries provided a realistic picture of the present and future of innovative businesses in this region (both SMEs and

\footnotetext{
${ }^{3}$ The research team was at that time itself based entirely in Germany, so this approach offered the benefits of speed and greater access to companies - although, naturally, it cannot be considered representative of Europe as a whole.
} 
larger players). Such a sample cannot, of course, be considered truly representative, but it does provide a solid foundation for understanding the issues and needs of SMEs within both present and future EU member nations.

We decided to design a very rich questionnaire which would provide us with the wide-ranging and detailed information we have described above, although we realised that this might have an adverse impact on the total number of respondents (as, indeed, it did). Nonetheless, we felt that the quality of the information we would obtain from our own survey (available from www.simproject.de) was sufficiently valuable to offset the comparatively small number of respondents it would draw.

To obtain the necessary data about each music industry stakeholder group, we designed separate questionnaires for each stakeholder category. During the expert talks we identified these categories as comprising: artists, labels/record companies, music portals, telcos/PTTs, internet service providers, payment system providers and technology providers. The stakeholder questionnaires were not completely different, but specific questions were designed for each stakeholder category to elicit data which were relevant only to that group.

The ultimate goal of our questionnaires was to collect sufficiently detailed information about each stakeholder category to enable the identification of a representative business model for each stakeholder - which could then be used by our SimWeb partners to build a multi-agent simulation of the music industry. As a by-product, we obtained relative frequency distributions from the total set of answers, which gave us a general impression of the current state of the music industry, with its interconnections and structure.

Since this research was essentially inductive - there were no existing data on the music industry to compare with and the theories so far developed are not yet sufficiently heuristic to make it useful to test them with empirical data - we were primarily concerned to gain a snapshot image of the market-place upon which the simulation could be based. In view of the preliminary state of the music market in Europe, and our overall goal of identifying 'typical' stakeholders for later development into agents, we were not endeavouring to test specific theories, nor did we have assumptions about connections of different variables in the sector. We had some general assumptions about the stakeholder groups within the music industry, drawn from our expert talks, and we were endeavouring to obtain more concrete information about these businesses to firm up our typologies and our business model definitions. When searching for market structures without having a specific theory in mind, descriptive statistics provide a sufficiently rigorous method of analysis - and our survey analysis is therefore essentially based on such analysis.
We obtained 191 responses from companies within the online music sector, plus 45 respondents which classified themselves as active in both the news and music sectors and which are therefore also included in this paper. The largest number of respondents came from the UK and Germany, with Spain and Italy being the next in terms of numbers of respondents.

\section{Findings}

\subsection{The Origin of Content}

With the advent of the Internet the artist has a new way of selling his/her songs, in addition to simply finding a record company to produce and later promote the music. S/he can now go directly to the end consumer of the music. This happens today via a Web site where the artist offers downloads, or even self-produced CDs, for sale. $50 \%$ of the artists answering our online questionnaire said they had their own Web site, 50\% had music published on a label's homepage; and the music of $16.7 \%$ was included in an MP3 platform ${ }^{4}$. $40 \%$ of our respondents are already charging for their digital music.

In every country there is an association which acts as an intermediary for musicians, concluding authorisation contracts with the songwriter or musician and simultaneously negotiating agreements concerning the licensing of that piece of music with a distributor or retailer. These associations exist to protect the intellectual property of a creative work - but also to ensure that anyone using the music is paying for the intellectual property (IP) embodied within it.

\subsection{Online Media Companies in the Music Sector}

The advent of digital access to music has created some major challenges for those companies producing and distributing music. Before the coming of the World Wide Web, the labels searched for new talent, produced particular artists' music and then promoted this music by means of music videos, concerts, advertising and various other events. The record companies also acted as distributors of the music CDs right through to the major retail outlets such as the French group FNAC or the German Media Markt chain (although small retailers purchase from wholesalers).

The Internet has, however, changed the record companies' place in the music value chain. Artists can now go directly to the end-consumer with their songs and the whole process of music distribution has changed

\footnotetext{
${ }^{4}$ These numbers are \% of cases, where there was "Multiple Entries Possible” (MEP). All questions where such multiple entries were possible therefore have a footnote stating MEP.
} 
significantly, leaving the labels with two major issues to resolve:

Firstly, they must now re-negotiate their existing contracts with their artists, because the contracts made prior to the advent of Internet technology permitted the record companies only to produce the CD and tape format for the corresponding piece of music. Now they need the right to produce the same music in digital format, which costs them significant amounts of money, because the artists insist on a higher percentage of the profit (up to $25 \%)$.

Secondly, the labels do not possess the necessary technological infrastructure to enable the distribution of digital music (we discuss the issue of record companies' desire to distribute music files later in the paper). It is therefore necessary for them to form joint ventures with companies such as telcos, ISPs, or providers of other types of technology. The external partners/ intermediaries most frequently identified by the labels in our survey were: network providers (57.4\%), payment system providers (56.9\%), billing system providers (36.2\%), software developers (40.9\%), platform providers (40.4\%) and telcos/PTTs (31.1\%). It is clear that some of these intermediaries are really the distributors of the music, rather than the labels. A good example of such an intermediary is OD2 (www.od2.com), which provides the technological infrastructure for music web sites such as the Tiscali Music Club (http://music.tiscali.co.uk) which offers digital music for download.

Though the deep structural changes and new challenges the labels generate Internet-based revenue mainly from content sales (34.7\%), merchandise sales (28.6\%), through newsletters (20.4\%) and by means of online advertising $(18.4 \%)^{5}$. Only $8.2 \%{ }^{6}$ gain income from revenue sharing. Some companies mentioned that they are currently using the Internet merely as a promotional tool to support their offline activities.

The record companies are beginning to worry that they may eventually lose their current market dominance and be restricted to the considerably more limited roles of talent finder, producer and promoter of music. But they are not yet moving to a new role in the digital world: Most of the labels in our survey see their core process of the production of digital music (88.6\%) - its distribution (28.4\%) and promotion (26.1\%), and the sale (25\%) of digital music were not seen as being of equal importance ${ }^{7}$. Though $85.5 \%$ of the respondent companies said that their strategic decisions were influenced by their customers, (43.4\% mentioned the financial situation, $37.3 \%$ the global economy and $33.7 \%$ their competitors),

\footnotetext{
5 MEP

6 MEP

7 MEP
}

the labels try to stick on the old structures ${ }^{8}$ (see Figure 1 for a summary of these findings).

According to our survey respondents, $75 \%$ of the labels produce the products they offer, $56.9 \%$ buy a license and $31.9 \%$ purchase the copyright ${ }^{9}$. The primary content source for $87.8 \%{ }^{10}$ of respondents was the artist. Audio streaming is offered by $67.2 \%$ of the labels free of charge, $60.4 \%$ of the labels do not offer any downloads, and a startling $80.9 \%$ do not offer the ability to transfer music to external devices or burn the music onto CD. Personalisation is also not very popular with the labels, with $85.1 \%$ offering no personalised products or services. Not surprisingly, given this reluctance to engage in online music access, in $62.9 \%$ of cases payment-per-product was the charging mechanism used, with $54.3 \%$ offering payment-per-download and only $17.1 \%$ permitting subscriptions ${ }^{11}$.

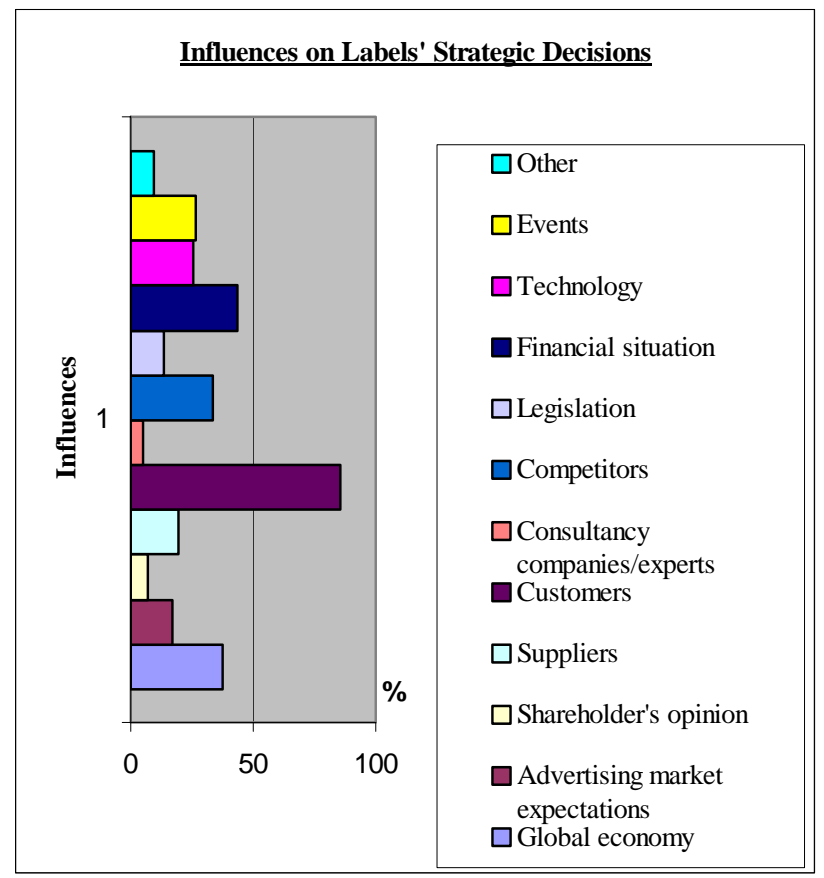

Figure 1. Influences on Labels’ Strategic Decisions

The music associations are now negotiating with (music) portals, rather than with the record companies, for licensing contracts. GEMA told us that they must write their contracts with the organisations which possess the music sales and value information and that they have come to realise that for online music it is the portals, telcos and ISPs which hold these data. Responding to the 
danger of losing some or all of their market power, the record companies are reacting in a variety of ways.

\subsection{Music Portals}

Many companies originally from other core competence areas or new founded Internet companies are now moving into the online music business. We divide three types of portals:

Music portals initiated by traditional retailers or intermediaries: these music portals were developed from companies which had been (some of which still are) retailers in the physical world. They use music downloads mainly for marketing reasons. For example, if visitors to the Web site are interested in a specific CD, they can download one song from a CD free of charge. The online retailers such as the French company FNAC, coming from the offline world, still lack access to the music industry catalogues either because these players are trying to do business on their own account online, or because they are concentrating on new, pure-play eTailers which are usually an offshoot of the telecommunications or technology industries.

Music portals initiated by telecommunications companies or technology providers: these are frequently spin-offs of telcos (for example, the Tiscali Music Club, created by the Italian telco Tiscali, and offering downloading, streaming and burning of digital music and news related to the music scene). A rather different example is od2.com, which specialises in secure online music distribution and which has recently begun to found music portals in cooperation with other companies - for example, dotmusic.com in conjunction with British Telecom and, still more recently, joint ventures with both Microsoft and Tiscali.

The real success story in terms of legal music downloads, of course, is Apple - whose iTunes Music Store has drawn the attention of potential rivals. iTunes, at the time of our survey only available in the US, enables users to move their 99-cent songs to an unlimited number of portable iPod players, and burn as many as 10 identical CDs containing the same play list. From a technical and Digital Rights Management point of view Apple has found a way to integrate P2P elements with the protection of property rights [27].

Britain's Wippit Ltd takes a different approach. Working with Gracenote's Cantametrix MusicDNA technology which 'maintains a database of fingerprints of tracks that are approved for sharing on the network; only those tracks can be shared among Wippit subscribers, who pay an annual fee of GBP 30 or US $\$ 45$ for unlimited downloads' [24], it offers both legal P2P download access, as well as making individual tunes available on a pay-per-download basis using the iTunes model.
Independent music portals: these organisations do not depend on any other company for their existence (although, of course, their music comes from the same sources as all other portals' music does). A particularly good example of an independent music portal is www.vitaminic.com, which offers 400,000 tracks from 91,000 artists and 1,400 labels (compared to www.popfile.de's 5,000 tracks), because it has built up a wide network of content partners, including BMG, Edel, EMI, Roadrunner, Sony, UMG, V2, WMG and several independent labels [20]. In consequence, the user can choose among a wide variety of songs without knowing which label produces the artist's music and can download them in MP3, Real Audio or WMA format. The simple payment scheme is another inducement to use this site. For unlimited downloads the user pays a subscription fee of $50 €$ for six months, or $81 €$ for a whole year.

Irrespective of type, $50 \%$ of all music portals in our survey said that they needed external support from Telcos/ PTTs and/or network providers. This also applied to payment system providers, subscription platform providers and billing system providers, all of whom required similar support. That means that cooperation, joint ventures, mergers and acquisitions become more and more important for a successful business strategy.

As a core process the portals cite the promotion of digital music (50\%) and they also distribute (41.7\%), sell (33.3\%) and add value to (33.3\%) digital music ${ }^{12}$ (see Figure 2). Their strategic decisions are mainly influenced by their customers $(83.3 \%)^{13}$.
12 MEP
13 MEP 


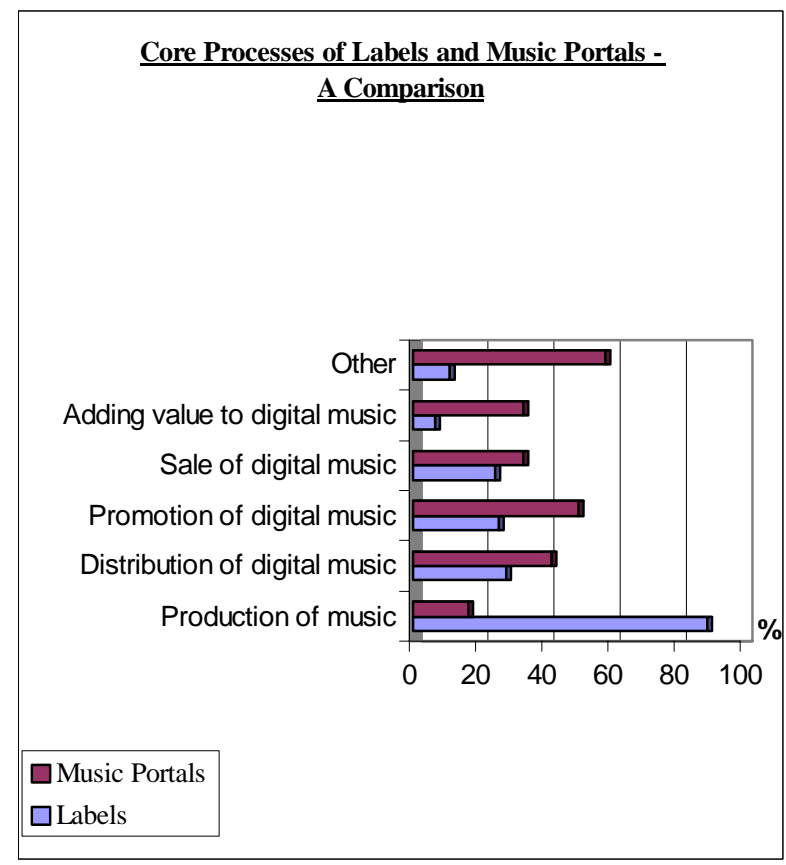

Figure 2. Core Processes of Labels and Music Portals - A Comparison

The digital music they sell is mostly acquired by licensing (37.5\%); producing and buying copyright are less common (both 25\%) ${ }^{14}$. Music portals obtain their music either directly from the artist (75\%) or from labels or record companies $(75 \%)^{15}$. $30 \%$ of the portals have contracts with more than 50 artists. Recently increasing numbers of music portals are contacting artists directly, to promote and distribute their music online.

The main income source of music portals is online advertising (50\%), followed by newsletter and content sales (both 37.5\%) and sponsorship and subscription $(25 \%)^{16}$. Music portals obviously have several income sources although, of the $28.6 \%$ which offer audio streaming, $14.3 \%$ charge and a further $14.3 \%$ do not charge money for this service. The same situation applies to downloading, where $28.6 \%$ charge, a further $28.6 \%$ do not charge and $42.6 \%$ don't offer downloads at all. $66.7 \%$ of portals offer personalised products and services (compared with $85.1 \%$ of the labels which do not offer personalised products) and 50\% charge for related products. The charging mechanisms used are: subscription (71.4\%), pay per download (71.4\%) and pay per product $(42.9 \%)^{17}$.

\subsection{Telecommunications companies and technology providers}

The telecommunications companies' core competence once lay in the supply of the physical telecommunications infrastructure. Today they need arguments to sell their technologies - ranging from broadband Internet access to mobile applications. One of the major arguments for the broad customer base is the supply of content which is either produced in-house or bought from content providers such as news agencies, media companies or freelancers. A two-way dependency exists: on the one hand the telcos need the content providers to add value to their pure telecommunications product; on the other hand content providers need telcos because they have such a broad customer base and because they physically deliver the content to the end consumer.

Content providers either do not have the expertise needed to maintain their own technology, or find it too expensive to do so and therefore seek partners who can provide this capability and who are willing to share it. Of course they also cooperate with ISPs or online portals, even though these are competitors. The united effort to win new customers and satisfy their needs forces these companies to move towards one another and creates coopetition. Revenue and the customer relationship must be shared in an adequate and mutually-agreed way. According to Gregg [9] content providers and telecommunications companies have the same problem in content selection, development of services and technological implementation. Why shouldn't they try to solve those problems together?

As an example, at the start of 2002 T-Online, part of the former German PTT Deutsche Telekom, started charging for the content and services used via the Internet access, as well as for "traditional" Internet access [28].

The companies in our survey mostly provide software (58.3\%), Internet application services (54.2\%), and payment systems $(50 \%)^{18} .80 \%$ say they provide the infrastructure for content providers. Revenue for this group of companies comes mostly from software sales (65\%), but also with $45 \%$ from other content sales. Revenue sharing and consultancy (each $40 \%$ ) contributes too $^{19}$. The most common charging mechanism is pay per download (68.8\%), followed by subscriptions $(43.8 \%)^{20}$.

\footnotetext{
14 MEP

15 MEP

16 MEP

17 MEP
}

${ }^{18}$ MEP
${ }^{19}$ MEP
${ }^{20}$ MEP 


\section{Conclusion - Key Driving Factors for the Online Music Industry}

Major issues identified by the survey included both positive and negative factors, including the legal problems of P2P downloads, as well as new methods of attracting customers online.

Despite the overwhelmingly negative comments reported in the press, we were surprised to find $68.9 \%$ of the labels in our survey believe they will develop successful business models to sell music over the Internet. But there seems to be uncertainty about how to deal with file sharing: $35.2 \%$ of our survey sample agreed that file sharing should be prosecuted, but the same number disagreed (29.6\% neither agreed nor disagreed). There is no absolute consensus on this issue among music industry representatives in Europe.

Our survey revealed that $40.8 \%$ of the labels will continue to offer digital content free of charge as a service to their customers, with only $12.2 \%$ already charging for content. $46.9 \%$ are planning to charge for digital content 2003 or 2004, what means that labels will start to change their business model - however.

The Internet is becoming a medium like TV or radio with which the user is spending more and more time. Companies need to see that they are moving into a new competitive environment where TV stations are competing with radio stations and with the Internet for customers' attention, as well as for their limited time and money

And the offers from all these market players are becoming more and more similar, making competition yet more difficult. Convergence in the online content sector is very clear, with former media companies, as well as companies previously offering telecommunications or technology provision, moving into the online content business. As Porter's [22] five forces model suggests, under these circumstances companies in the online music sector are facing more and more competitors online than ever they did in the offline world - and many more than they did only a year ago!

In consequence of these higher levels of competition, companies have to try to sharpen their own profile by emphasising their core competence(s). Porter and Millar's [23] competitive strategies suggest the alternatives of price leadership, differentiation, or niche marketing. All three of these strategies are already in evidence: niche markets - whether at the content level, the regional level or the technology level - are an existing alternative for many online music providers. Apple's iTunes has already shown the benefits of differentiation and competitors; and imitators such as RealNetworks will soon make the price leadership issue a major factor.

Another approach we are starting to see is joint venture cooperation to offer something unique - or at least something very attractive. For example, content providers and Internet service providers are already working together to offer a joint product to the customers of both companies (e.g. od2 and BT) or even offering a competitor's product or service to their own customer base. Coopetition of this sort is generally based on revenue sharing - and $64.3 \%$ of the telecommunications and technology providers in our survey believe that content providers will not survive unless revenue is shared.

The content industry is also very dependant on the end devices by which the content is delivered to, and used by, customers. The technologies in this area are blending and converging. Mobile phones, digital cameras and MP3 players are already being offered as a single device. Linked to the end devices is the emergent UMTS technology ( $3^{\text {rd }}$ generation mobile phones) which will allow content providers to sell their content to mobile devices at an acceptable time and (hopefully) an acceptable price. In this area there is enormous potential for further revenue because telephone bills offer the potential to solve the entire problem of usable and accepted payment systems [11].

A further driving factor for the online content industry is the consumers themselves. The Internet has made it possible to access - in a simple, fast, convenient and relatively cheap manner - information or music or, indeed, content in general. Consumers on the Web have more power over their buying decisions than they do in the real world. The next offer is only a click away and could even contain, in the case of online music, a free offer from another consumer (in peer-to-peer networks). The expectations of online customers are still very different from those of offline customers, even though the average Internet user is becoming increasingly similar to the 'average' citizen.

In view of the obvious differences between online and offline companies and their customers which emerged from our survey, it was surprising to discover that these 'new' companies are still targeting a primarily male (92\%) and experienced (87.7\%) Internet user base. A more entrepreneurial approach might be to target a broader range of potential customers online. Young people, in particular, are growing up with the Internet, getting used to free content (and know exactly where and how to get what they want) and are very price-conscious. Why not encourage them to become accustomed to paid content? $61.5 \%$ of the telecommunications and technology companies in our online survey are already charging for digital content, and $42.9 \%$ charge for personalised content and services. Content providers such as the media companies are, however, still hesitating.

The Internet is becoming too important a sales channel to allow it to develop itself. At the moment it appears that the record companies are more driven by the market than 
driving it. The emergence of more and more music portals on the Internet is marked by the involvement of telecommunications and technology companies (compare e.g. www.dotmusic.co.uk with www.popfile.de ). This shows how important the appropriate know-how in this area is for developing a promising business model in online music. Telecommunications and technology providers are happy to charge for the content and the services they offer (and why not?). Using the Internet as a promotional tool, as the makers of "The Offspring" did, could be a successful way of integrating the Internet into a multi-channel marketing and delivery strategy. Before they released their self-titled album "Americana", the group offered free downloads on the Internet (20 million copies were downloaded) and still sold 12 million CDs [8].

The Internet offers almost unlimited potential for marketing, for selling and for using customer information and buying history to maximise profits. But none of this is possible unless the companies concerned are willing to throw away their pre-conceived ideas of how business must be done - and accept that in this brave new world, new ways of doing business and new business models are the norm. The only certainty for the digital content industry is that there is not certainty!

\section{References}

[1] Bhatia, G.R., C.G. Krishan and W.R. Honey (2003), "Windows into the Future: How Lessons from Hollywood will Shape the Music Industry”, Journal of Interactive Marketing, 17 (2), 70-80.

[2] Clemons, E.K., B. Gu and K.R. Lang (2002), Newly Vulnerable Markets in an Age of Pure Information Products: An Analysis of Online Music and Online News, in: Proceedings of the 35th HICSS

[3] De Vaus, D.A. (1995), Surveys in Social Research (4th Edition). Allen and Unwin, NSW, Australia

[4] Durlacher (2001), Impacts of Digital Distribution on the Music Industry, Research Report.

[5] Gable, G. G. (1994), "Integrating Case Study and Survey Research Methods: An Example in Information Systems", European Journal of Information Systems, 3(2), 112-126.

[6] Galliers, R. D. (1991), Choosing Appropriate Information Systems Research Approaches: a revised taxonomy in Information Systems Research: Contemporary Approaches and Emerging Traditions (Eds) H.-E. Nissen, H.K. Klein and R. Hirschheim, Elsevier Science Publishers, 327-345.

[7] Gehrke, N. and M. Anding (2003), A Peer-to-Peer Business Model for the Music Industry, in: J.L. Monteiro et al. (Eds.), Towards the Knowledge Society-eCommerce, eBusiness and eGovernment, Boston, 243-258.

[8] Gitnick, A., F. Kurniawan, P. Ma and S. Milawijaya (2000), E-Business Impact On Retail In The Music Industry, Class Project Report (Business Administration Course 147, Fundamentals of E-Business, Fall 2000, University of California, Berkeley), Berkeley.
[9] Gregg, S. (2001), Die Konvergenz: Telekommunikationsanbieter und Medienunternehmen Wettbewerber oder Partner?, in: A. Vizjak and M. Ringlstetter, Medienmanagement: Content gewinnbringend nutzen, Trends, Business-Modelle, Erfolgsfaktoren, Wiesbaden, 37-44.

[10] Grover, V. (2000), A Tutorial on Survey Research: From Constructs to Theory, available online at: http://dmsweb.badm.sc.edu/grover/survey/MIS-SUVY.html

[11] Hampe, J. F., P. M. C. Swatman and P. A. Swatman (2000), Mobile Electronic Commerce: Reintermediation in the Payment System, "Bled'2000" - 13th Bled International Electronic Commerce Conference, Bled, Slovenia, June 19-21, 693-706.

[12] IFPI (2002), Jahrbuch 2002, Phonographische Wirtschaft, Bundesverband der Phonographischen Wirtschaft e. V. (Ed.).

[13] IFPI (2004), Online Music Report 2004, available online at: http://www.ifpi.com.

[14] Kaplan, B. and Duchon, D. (1988), "Combining qualitative and quantitative methods in information systems research: a case study”, MIS Quarterly, 12(4), 571-586.

[15] Kwok, S. H., K.R. Lang and K.Y. Tam (2002), "Peerto-Peer Technology Business and Service Models: Risks and Opportunities”, Electronic Markets, 12 (3), 175-83.

[16] Lam, C. K. M. and B. C.Y. Tan (2001), "The Internet is changing the Music Industry", Communications of the ACM, Vol.44, No. 8, pp. 62-68.

[17] Lechner, U. and J. Hummel (2002), "Business Models and System Architectures of Virtual Communities: From a Sociological Phenomenon to Peer-to-Peer Architectures”, International Journal of Electronic Commerce, 6 (3), 41-53.

[18] Lee, A.S. (1991), "Integrating Positivist and Interpretive Approaches to Organisational Research”, Organisational Science, 2(4), 342-365.

[19] MacElroy, B. (1999), Comparing seven forms of on-line surveying, in: Quirk's Marketing Research Review, Article No. 0510, July, available online at: http://www.quirks.com/articles/article_print.asp?arg_articleid=5 $\underline{10}$.

[20] Momag.net (2003), Politik bei Copyright, Mehrwertsteuer, Export und Radioquote gefordert, available online

http://momag.net/mag/2003.02/phono2003/index2.php, accessed: 5/3/2003

[21] Oberholzer, F. and K. Strumpf (2004), The Effect of File Sharing on Record Sales: An Empirical Analysis, available online

http://www.unc.edu/ cigar/papers/FileSharing_March2004.pdf

[22] Porter, M.E. (1980), Competitor Strategy, Free Press, USA.

[23] Porter, M.E. and Millar, V.E. (1985), "How information gives you competitive advantage”, Harvard Business Review, Mar-Apr, 134-142.

[24] Rosenblatt B. (2004), Two Major Labels Wippit, DRM Watch, available online at: http://www.drmwatch.com/ocr/article.php/3327821

[25] Schoder, D. and K. Fischbach (2003), "Peer-to-Peer Prospects”, Communications of the ACM, 46 (2), 27-29.

[26] Smith, C. B. (1997), "Casting the Net: Surveying an Internet Population”, Journal of Computer Mediated 
Communication, 3(1), available online at: http://www.ascusc.org/jcmc/vol3/issue1/smith.html .

[27] von Walter, B. and T. Hess (2003), „,iTunes Music Store - Eine innovative Dienstleistung zur Durchsetzung von Property-Rights im Internet“, Wirtschaftsinformatik, 45 (5), 541-46.

[28] Wirtschaftswoche (2002), Schluss mit gratis, 3.1.2002, $\mathrm{N}^{\circ} 1 / 2,46 \mathrm{f}$

[29] Yin, R.K. (1994), Case Study Research: Design and Methods (2nd Edition), Sage Publications, USA. 